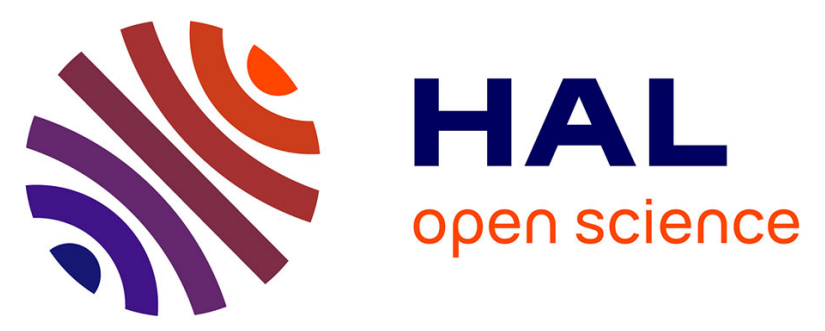

\title{
Targeting the NRG1/HER3 pathway in tumor cells and cancer-associated fibroblasts with an anti-neuregulin 1 antibody inhibits tumor growth in pre-clinical models of pancreatic cancer
}

Charline Ogier, Pierre-Emmanuel Colombo, Corinne Bousquet, Lucile Canterel-Thouennon, Pierre Sicard, Véronique Garambois, Gaëlle Thomas, Nadège Gaborit, Marta Jarlier, Nelly Pirot, et al.

\section{- To cite this version:}

Charline Ogier, Pierre-Emmanuel Colombo, Corinne Bousquet, Lucile Canterel-Thouennon, Pierre Sicard, et al.. Targeting the NRG1/HER3 pathway in tumor cells and cancer-associated fibroblasts with an anti-neuregulin 1 antibody inhibits tumor growth in pre-clinical models of pancreatic cancer. Cancer Letters, 2018, 432, pp.227-236. 10.1016/j.canlet.2018.06.023 . hal-02350723

\section{HAL Id: hal-02350723 \\ https://hal.science/hal-02350723}

Submitted on 6 Nov 2019

HAL is a multi-disciplinary open access archive for the deposit and dissemination of scientific research documents, whether they are published or not. The documents may come from teaching and research institutions in France or abroad, or from public or private research centers.
L'archive ouverte pluridisciplinaire HAL, est destinée au dépôt et à la diffusion de documents scientifiques de niveau recherche, publiés ou non, émanant des établissements d'enseignement et de recherche français ou étrangers, des laboratoires publics ou privés. 
Targeting the NRG1/HER3 pathway in tumor cells and cancer-associated fibroblasts with an anti-neuregulin 1 antibody inhibits tumor growth in pre-clinical models of pancreatic cancer

Running title: Anti-NRG1 antibody in pancreatic cancer treatment.

Charline Ogier ${ }^{\mathrm{a}}$, Pierre-Emmanuel Colombo ${ }^{\mathrm{ab}}$, Corinne Bousquet ${ }^{\mathrm{c}}$, Lucile Canterel-Thouennon ${ }^{\mathrm{a}}$, Pierre Sicard ${ }^{d}$, Véronique Garambois ${ }^{a}$, Gaëlle Thomas ${ }^{a}$, Nadège Gaborit ${ }^{a}$, Marta Jarlier ${ }^{b}$, Nelly Pirot $^{a}{ }^{2}$ Martine Pugnière $^{\mathrm{a}}$, Nadia Vie ${ }^{\mathrm{a}}$, Céline Gongora ${ }^{\mathrm{a}}$, Pierre Martineau ${ }^{\mathrm{a}}$, Bruno Robert $^{\mathrm{a}}$, André Pèlegrin ${ }^{\mathrm{a}}$, Thierry Chardès $^{\mathrm{a}}$, Christel Larbouret ${ }^{\mathrm{a}}$

a IRCM, Institut de Recherche en Cancérologie de Montpellier, INSERM U1194, Université de Montpellier, Institut régional du Cancer de Montpellier, Montpellier, F-34298, France.

bInstitut régional du Cancer de Montpellier (ICM), Val d'Aurelle, Montpellier, , F-34298, France

${ }^{\circ}$ Cancer Research Center of Toulouse (CRCT), INSERM UMR 1037-University Toulouse III Paul Sabatier, Toulouse, France

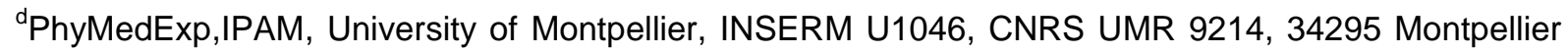
cedex 5, France

Corresponding Author: Address reprint requests to Christel Larbouret, PhD, Institut de Recherche en Cancérologie de Montpellier, Campus ICM, 34298 Montpellier Cedex 5, France; E-mail: christel.larbouret@inserm.fr; phone: 33 (0) 467612518; Fax: 33 (0) 467613787.

Funding: This work was supported by grants from the Ligue Nationale Contre le Cancer, Comité de I'Hérault, from the LabEx Mablmprove (ANR-10-LABX-53-01), from the SIRIC Montpellier Cancer “INCa-DGOS-INSERM 6045” from the Cancéropole Grand Sud Ouest.

Conflicts of interest: Charline Ogier, Christel Larbouret, Thierry Chardès and André Pèlegrin are inventors in the anti-NRG1 mAb patents related to this work. The other authors declare no conflict of interest. 


\section{ABSTRACT}

Neuregulin 1 (NRG1), a ligand for HER3 and HER4 receptors, is secreted by both pancreatic tumor cells $(\mathrm{PC})$ and cancer-associated fibroblasts (CAFs), the latter representing the most abundant compound of pancreatic stroma. This desmoplastic stroma contributes to Pancreatic Ductal Adenocarcinoma (PDAC) aggressiveness and therapeutic failure by promoting tumor progression, invasion and resistance to chemotherapies. In the present work, we aimed at disrupting the complex crosstalk between PC and CAF in order to prevent tumor cell proliferation. To do so, we demonstrated the promising tumor growth inhibitory effect of the 7E3, an original antibody directed to NRG1. This antibody promotes antibody dependent cellular cytotoxicity in NRG1-positive PC and CAFs and inhibits NRG1-associated signaling pathway induction, by blocking NRG1-mediated HER3 activation. Moreover, 7E3 inhibits migration and growth of pancreatic cancer cells co-cultured with CAFs, both in vitro and in vivo using orthotopic pancreatic tumor xenografts. Our preclinical results demonstrate that the anti-NRG1 antibody 7E3 could represent a promising approach to target pancreatic stroma and cancer cells, thereby providing novel therapeutic options for PDAC.

Key words: immunotherapy, neuregulin 1, HER3, pancreatic cancer, cancer-associated fibroblast

Abbreviations: PC: pancreatic cancer, $\mathrm{CM}$ : condition medium, CAF: cancer associated fibroblast 


\section{INTRODUCTION}

Pancreatic cancer remains one of the most aggressive tumors with an extremely poor prognosis and is estimated to become the second leading cause of cancer-related death by $2030[1,2]$. This dramatic outcome is related to the lack of efficient therapeutic tools, early diagnostic markers, and high resistance to chemotherapy.

Abundant desmoplastic reaction is a prominent feature of pancreatic cancer and constitutes up to $80 \%$ of the total tumor volume. It is characterized by the presence mainly of cancer-associated fibroblasts (CAFs), but also of immune cells, vasculature, and extracellular matrix (ECM). These stroma characteristics contribute to pancreatic cancer aggressivity and therapeutic failure because they promote tumor progression, invasion and resistance to chemotherapies $[3,4]$. Once activated, CAFs express alpha smooth muscle actin ( $\alpha$ SMA) and secrete ECM and soluble factors (e.g., growth and inflammatory factors) that stimulate tumor growth and mediate inflammation. In preclinical studies, stroma disruption, by direct CAF targeting (hedgehog signaling inhibitors) [5] or by ECM enzymatic digestion (hyaluronidase), results in tumor inhibition and increases drug delivery [6]; however, controversial or disappointing results were reported by clinical trials. Moreover, recent studies have questioned CAF role in pancreatic tumor maintenance and highlighted the need of caution when targeting CAFs [7-9]. Indeed, several evidences indicate that there are different CAF subtypes with different functions $[10,11]$. Therefore, characterization of these subtypes is needed to enable the specific targeting of CAFs with pro-tumor features.

Neuregulins (NRGs) are large polypeptide growth factors that are part of the EGF family of proteins. They are encoded by four genes (NRG1-4) that are subject to extensive alternative mRNA splicing, leading to more than 30 variants grouped in six types $(\mathrm{I}-\mathrm{VI})$ with a distinct $\mathrm{N}$-terminal part. NRG1 and 2 are both HER3 and HER4 ligands and have at least two splice alternatives in their EGF-like domains, resulting in $\alpha$ and $\beta$ isoforms. NRG1 $\beta$ has higher binding affinity for HER3 through HER2-dependent recruitment [12]. NRG3 and 4 bind only to HER4. Most isoforms are synthetized as transmembrane molecules with the EGF-like domain in the extracellular space and are released as soluble factors by cell surface proteases. Binding to the EGF-like domain of NRG1 promotes HER3 or HER4 conformational changes, leading to their dimerization and activation that result in the phosphorylation of downstream signaling molecules. Several evidences indicate that NRG1 contributes to the development and progression of different tumor types, such as breast, prostate or pancreatic cancer 
[13-16]. High NRG1 expression has been correlated with poor prognosis in breast cancer, head and neck squamous cell carcinoma and pancreatic cancer [13-15]. In addition, NRG1 downregulation by antisense oligonucleotides, or NRG1 signaling inhibition by competitive binding of a shorter HER3 isoform reduces breast cancer cell proliferation and migration [16, 17]. Furthermore, the crosstalk between NRG1 and HER3 is involved in resistance to chemo- and targeted therapies through the maintenance of oncogenic signaling pathways [18].

Several studies reported that not only EGF family growth factors but also their receptors play an important role in pancreatic cancer development. Expression of EGFR, HER2 and HER3 has been examined in pancreatic ductal carcinoma and correlated with advanced disease and poor prognosis [19-22]. HER4 expression has not been examined as extensively and its prognostic value is not known.

Disruption of intracellular communications between stromal and cancer cells could affect tumor proliferation and represents an interesting therapeutic strategy. In this context, we hypothesized that targeting NRG, which we here show to be secreted both by CAFs and tumor cells, could be a novel therapy to overcome CAF-triggered tumor growth in pancreatic cancer. Here, we investigated, in in vivo and in vitro co-culture of pancreatic cancer cells and CAFs, the therapeutic potential of an original monoclonal antibody (7E3) that targets NRG1 Ig-like domain. We show promising tumor growth inhibitory effects of this antibody which promotes antibody dependent cellular cytotoxicity (ADCC) in NRG1-permeated pancreatic cancer cells and in NRG1-positive CAFs and blocks NRG1-mediated HER3 activation and downstream signaling pathway induction. 


\section{MATERIALS AND METHODS}

\subsection{Cell lines and reagents}

The BxPC-3, CFPAC-1, HPAC, AsPC-1, SW1990, MiaPaCa-2 and MCF7 cancer cell lines were obtained from ATCC (Rockville, MD, USA) and cultured following the ATCC recommendations. The identity of cell lines was confirmed by genetics authentification test (Eurofins, Ebersberg). BxPC-3Luc, HPAC-Luc, shHER3 BxPC-3 and shluc BxPC-3 cells were generated previously in the laboratory [23]. Stably-transfected AsPC-1-Mock (vector alone) and AsPC-1-NRG1 cells were obtained as previously described for pMSCV-hygro-NRG1(OriGene) [24].

RhNRG131-ECD and HER3-Fc were purchased from RD Systems (Minneapolis, MN). All antibodies used in western blot were from Cell Signaling Technology (Beverly, MA). Antibodies against HER3 (16D3-C1) and CEA (35A7) were generated previously in the laboratory [25].

\subsection{Human CAF isolation and cell culture}

CAFs were isolated from human PDAC samples using the outgrowth method described by Duluc [26]. CAFs were cultured in Dulbecco's modified Eagle's medium F12 (DMEM/F12) with $10 \%$ decomplemented fetal calf serum (FCS, Life Technologies). CAF-CM was recovered from $10^{6} \mathrm{CAFs}$ cultured in DMEM/F12 without FCS for 48 hours. Primary normal pancreatic fibroblasts were kindly provided by Corinne Bousquet (CRCT, Toulouse). Normal Pancreatic Cells (NPC) were obtained from healthy human specimen from ICM hospital (Montpellier).

\subsection{Quantitative PCR for NRG1 expression analysis}

RNA was isolated using the Quick-RNA MiniPrep Kit (Zymo Research Corp., Irvine, CA) according to the manufacturer's protocol. RNA samples were first reverse-transcribed using the SuperScript III reverse transcriptase (Thermo Fisher Scientific, Waltham, MA) according to the manufacturer's protocol. Gene expression was then assessed by quantitative PCR using the Light Cycler 480 SYBR Green I Master Mix (Clontech). The primer sequences used for hNRG1 are Forward 5'ACCAGAAGAGAGTGCTGACC-3' Reverse 5'-CCAGAAGAGAGTGCTGACCA-3' and Forward 5'CCACTGGGACAAGCCATCTT-3' Reverse 5'- TTCACCATGAAGCACTCCCC-3'. Concentrations of mRNA were normalized to the concentration of the housekeeping gene HPRT, and expressed relatively to the lower cells expressing NRG1 (CFPAC=1).

\subsection{NRG1 secretion analysis}


Conditioned medium were analyzed using the NRG1 $\beta 1$ human ELISA kit (Abcam) according the manufacturer instructions. Concentrations were calculated from standard curve and data are representative of two independent experiments.

\subsection{Generation of monoclonal antibodies}

BALB/c mice were immunized with $10 \mu \mathrm{g}$ rhNRG1 $\beta 1$-EDC by subcutaneous injection as described previously [25]. Antibodies were produced by Biotem (Apprieu, France) and stored at $-20^{\circ} \mathrm{C}$ in phosphate buffered saline (PBS).

\subsection{Epitope mapping}

213 overlapping dodecapeptides that were frame-shifted by one or three residues and that covered the entire amino acid sequence of human NRG1 $\beta 1$ ECD were synthesized on cellulose membrane and epitope mapping was performed as already described [23]. For SPOT alanine scanning analysis, three pentadecapeptides corresponding to the identified antibody-immunoreactive sequences and the 13 alanine analogs of each peptide were synthesized by using the SPOT method. The antibody reactivity of cellulose-bound peptides was assayed as described above. SPOT reactivity was evaluated by scanning the membranes and measuring the spot intensities with ImageJ 1.44 (http://rsbweb.nih.gov/ij).

\subsection{Western blot analysis}

Western blotting was performed using cell protein lysates as described previously [49]. Band intensity was analyzed with the G:BOX imaging system (Syngene,Cambridge, UK).

\subsection{Cell proliferation assay}

The effect of the anti-NRG1 antibody 7E3 on cell proliferation and cell viability was evaluated using luciferase activity assays and sulforhodamine B (SRB) colorimetric assays, respectively. Cells were incubated with serum-free medium for $24 \mathrm{~h}$ and with RhNRG1 1 1-ECD and antibodies. After 5 days of incubation, the luciferine substrate (Promega, Madison, WI) added to the cells. Bioluminescence was determined using the Wallac Trilux 1450 Microbeta liquid scintillation and luminescence counter (Perkin-Elmer, Wellesley, MA). For SRB revelation, cells were fixed with cold $10 \%$ trichloroacetic acid and stained with SRB (Sigma, St Louis, MO). The protein-bound dye was dissolved in $10 \mathrm{mM}$ unbuffered Tris base solution, and the $\mathrm{OD}_{540}$ was read using a microplate reader. Growth inhibition was calculated based on the percentage of proliferating cells in treated samples relative to untreated cultures. All experiments were performed three times. 


\subsection{Cell migration (wound healing) assay}

Cells were seeded in 6-well plates and grown at $37^{\circ} \mathrm{C}$ in RPMI medium with $10 \%$ FBS as previously described [27]. Cells were incubated in serum-free medium with rhNRG1ß1-ECD and/or 7E3 or IR antibody. Cell migration was observed $48 \mathrm{~h}$ after and images captured using a Nikon TS100 microscope and an Olympus SP-510 UZ camera.

\subsection{D-growth assay}

Cells were washed in PBS, trypsinized, and prepared in RPMI with $2 \%$ FCS and $20 \%$ methyl cellulose for spheroid formation in ultra-low attachment 96 -well black plates. After $24 \mathrm{~h}$, cells were incubated with $50 \mathrm{ng} / \mathrm{ml}$ of $\mathrm{rhNRG} 1 \beta 1-\mathrm{ECD}$ and $50-100 \mu \mathrm{g} / \mathrm{ml}$ of $7 \mathrm{E} 3$ or IR antibody. After 10 days of incubation, $25 \mu \mathrm{l}$ of calcein-EthD-1 master mix was added to each well. After $30 \mathrm{~min}$, fluorescence was counted and cells analyzed with a Celigo Image Cytometer using the "Tumorosphere" application for spheroid area measurement (Nexcelom Bioscience, Lawrence, MA). All experiments were performed three times.

\subsection{Antibody internalization}

Cells were grown with serum-free medium for $24 \mathrm{~h}$ and were then incubated or not with $50 \mathrm{ng} / \mathrm{ml}$ rhNRG1 $\beta 1-E C D$ for $10 \mathrm{~min}$ and then with $30 \mu \mathrm{g} / \mathrm{ml}$ of anti-NRG1, -HER3, -CEA antibodies or RPMI alone (negative control) at $4^{\circ} \mathrm{C}$ or $37^{\circ} \mathrm{C}$. At different time points, cells were fixed and permeabilized in $3.7 \%$ formaldehyde/PBS, saturated with PBS/1\%BSA and finally incubated with AlexaFluor 488conjugated goat anti-mouse IgGs (1:100) (Cell Signaling Technology, Danvers, MA). Coverslips were mounted with EverBrite ${ }^{\mathrm{TM}}$ Hardest Mounting Medium with DAPI (Biotium, Inc., Fremont, CA) and analyzed the day after with a Zeiss Axioplan 2 Imaging microscope.

\subsection{Immunofluorescence}

Fibroblasts were plated on coverslips in RPMI medium with $10 \%$ FBS at $37^{\circ} \mathrm{C}$. Two days after, cells were fixed and permeabilized with $3.7 \%$ formaldehyde/PBS, saturated with PBS/1\%BSA and finally incubated with a monoclonal anti-vimentin Cy3 conjugate (1:600) or anti-actin or -aSMA FITC conjugates (1:100) (Sigma).

\subsection{Surface Plasmon Resonance analysis}

SPR experiments were performed using a Biacore T200 and a Biacore 3000 instrument as already described [48]. Briefly, HER3-Fc was captured on the CM5 sensor chip surface (2200 RU) using the 
anti-human Fc Capture Kit from GE Healthcare (Chicago, IL). Then, rhNRG1 $\beta 1$-ECD was injected at $185 \mathrm{nM}$ followed by an injection of 200nM 7E3 antibody or buffer at $30 \mu \mathrm{l} / \mathrm{min}$.

\subsection{ADCC assay}

LDH release was investigated with the CytoTox Non-Radioactive Cytotoxicity Assay (Promega). Shluc BxPC-3 or sh-HER3 BxPC-3 cells were incubated with $50 \mathrm{ng} / \mathrm{ml} \mathrm{rhNRG} 1 \beta 1-\mathrm{ECD}$ plus $50 \mu \mathrm{g} / \mathrm{ml}$ 7E3 or IR antibody for 30min, then hPBMC isolated with Ficoll from samples purchased from Etablissement Français du Sang (Montpellier, France) were added to the wells at a ratio of 1/15 (target:effector) for $24 \mathrm{~h}$. The same assay was done with CAFs without rhNRG1 $\beta 1-E C D$. The cell lysis percentage was calculated using the following formula: (bioluminescence at the experimental point basal bioluminescence) / (total lysis bioluminescence - basal bioluminescence) X 100. The basal luminescence value corresponded to cells incubated with hPBMC alone, and the total lysis bioluminescence value was obtained after cell incubation with $0.1 \%$ SDS for $30 \mathrm{~min}$.

\subsection{Tumor xenografts and treatment}

All in vivo experiments were performed in compliance with the French regulations and ethical guidelines for experimental animal studies in an accredited establishment (Agreement No. C34-17227). Pancreatic cancer cells $\left(3.5 \times 10^{6}\right)$ were injected subcutaneously into the right flank of 6 -week-old female athymic mice, purchased from Envigo (Le Malcourlet, France). Tumor-bearing mice were treated with $10 \mathrm{mg} / \mathrm{kg}$ of 7E3 or IR antibody by intraperitoneally injection twice a week for 4 or 6 weeks. Tumor volumes were calculated by using the formula: $D_{1} \times D_{2} \times D_{3} / 2$.

For orthotopic xenografts, $1 \times 10^{6}$ BxPC-3-Luc cells in $30 \mu \mathrm{l}$ PBS were injected in the pancreas of athymic mice, and 7 days post-graft, mice were treated as indicated above, but for 6 weeks. Tumor growth was monitored by bioluminescence detection as described previously [28]. At the end of the experiment (maximum bioluminescence signal in untreated animals), mice were sacrificed and bioluminescence in pancreas measured. For orthotopic co-xenograft experiments, a 1:2 mixture of BxPC-3 cells and CAFs was injected in the pancreas of athymic mice. Treatment started one weeks after grafting after randomization in two groups. Tumor growth was monitored by high-resolution 3D ultrasonic imaging (Vevo2100®, VisualSonics Inc.) using a Vevo2100 ultrasound scanner with a MS550D probe (22-55 MHz). Each tumor was scanned using 3D mode under respiratory gating. The $3 \mathrm{D}$ images of the tumor were manually contoured along the tumor margin throughout the 3D stack. The tumor volume was measured using parallel segmentation in the Vevo2100 software (version 3.0, 
VisualSonics Inc.). At the end of the experiment, the pancreas were weighted.

2.16. Immunohistochemistry

Immunohistochemistry was performed as described previously [27]. Quantification was done with Image Scope software.

2.17. Statistical Analysis

Statistical analysis of in vivo experiments was performed using the STATA 11.0 software (StataCorp., College Station, TX) as previously described [28]. 


\section{RESULTS}

3.1. NRG1 regulates pancreatic tumor growth in an autocrine and paracrine manner

RT-qPCR expression analysis showed NRG1 expression in 17/33 (51.5\%) pancreatic tumor samples

(Figure 1A). Then, NRG1ß1 gene expression was assessed in five KRAS-mutated pancreatic cancer cell lines and one KRAS-wild type cell line (BxPC-3). BxPC3, CFPAC and SW1990 cells expressed NRG1, whereas HPAC, MiaPaca2 and AsPC-1 did not (Figure 1B). As positive control, we developed a NRG1 positive cell derived of AsPC-1 (AsPC-1-NRG1 cells). As negative control, we used normal pancreatic cells (NPC). By ELISA, we measured the concentration of NRG1 secretion in medium. This expression correlated this NRG1 mRNA expression. As previously described [23]., all cell lines, with the exception of MiaPaCa-2 cells, expressed HER3, but not HER4.

NRG1 role in pancreatic tumor cell growth was supported by the finding that cell growth was higher (2.5-fold) in AsPC-1-NRG1 cells than in AsPC-1-Mock cells (Figure 1C, middle panel). Similarly, AsPC-1-NRG1 tumors collected 40 days after cell xenograft in mice were heavier than AsPC-1-Mock tumors (mean weight: $1.26 \mathrm{~g}$ vs $0.73 \mathrm{~g} ; \mathrm{p}=0.0117$ ) (Figure $1 \mathrm{C}$, lower panel).

Interestingly, we observed that CAFs isolated from pancreatic ductal adenocarcinoma (PDAC) specimens, also expressed NRG1 $\beta 1$ (Figure 1D). After 10 days of culture, CAFs exhibited a fibroblastlike phenotype, as shown by immunofluorescence expression of vimentin in sample CAF11, and were considered as activated, based on $\alpha$ SMA expression (Figure 1D). In comparison, normal pancreatic fibroblasts (NPF) expressed vimentin, but not $\alpha$ SMA, and therefore, were considered as not activated (Figure 1D). NRG1 mRNA was expressed in five of the six CAF preparations (Figure 1E). Conditioned medium (CM) from these CAF cultures expressed NRG1 as measured by ELISA assay and induced phosphorylation of HER3 in BxPC-3 cells (Figure 1F), except for the CM from CAF8 that did not express NRG1.

Altogether, these results demonstrated that NRG1 is expressed in both pancreatic tumor cells and CAFs and regulates pancreatic tumor growth in an autocrine or paracrine manner.

3.2. The NRG1-specific antibody 7E3 binds to NRG1 Ig-like domain and promotes ADCC towards pancreatic cancer cells in which NRG1 is complexed with HER3

The specific anti-NRG1 antibody 7E3 was generated by immunizing mice with recombinant human

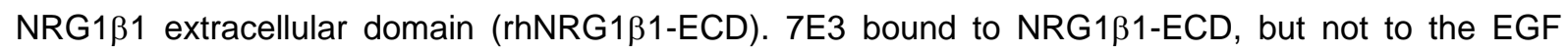


domain of NRG1 $\alpha$ and NRG1 $\beta, N R G 1 \beta 3$ SMDF nor to the related growth factors EGF, GAS6, AREG and HB-EGF (Supplementary Figure 1A). Surface plasmon resonance (SPR) analysis showed that 7E3 bound to rhNRG1 $\beta 1$-ECD with an affinity of $1.05 \mathrm{nM}$ (Supplementary Figure 1B), close to that of NRG1 binding to HER3 (1.6 nM). However, 7E3 still bound to recombinant NRG1 pre-complexed with HER3-Fc with similar affinity as for NRG1 alone (Figure 2A). This suggested that besides its ligand trapping activity, 7E3 could also be used to target HER3-bound NRG1. This was confirmed by immunofluorescence cell analysis, measuring 7E3 ability to recognize NRG1 when bound to HER3 at the cell surface of BxPC-3 cells expressing or not HER3 upon HER3 silencing (shHER3 BxPC-3 cells shLuc BxPC-3 control cells) (Figure 2B). The 7E3 antibody bound to rhNRG1 $\beta 1-E C D$ complexed to membrane-expressed HER3 in shLuc BxPC-3, but not in shHER3 BxPC-3 cells.

Using the SPOT method, we identified the epitope recognized by 7E3 located in the IgG-like domain of NRG1ß1 N-terminus. This explains why 7E3 still binds to NRG1 complexed to HER3, this NRG1/HER3 interaction requiring the EGF-like domain of NRG1. This also explains why 7E3 does not bind to the EGF domain of NRG1 $\alpha$ or of NRG1 $\beta$, nor NRG1 $\beta 3$ SMDF which does not contain the Iglike domain (Supplementary Figure 1A). Alanine scanning analysis (Figure 2C) indicated that the ${ }^{154}$ IRISV ${ }^{158}$ sequence in NRG1 Ig-like domain was the binding motif and residues $R^{155}$ and $V^{158}$ the main contributors.

As 7E3 can bind to NRG1 complexed to HER3, ADCC assays, were performed to test whether 7E3 could activate immune cells (Figure 2D). To do so, human peripheral blood mononuclear cells (hPBMC) were used as effector cells, and shHER3 or shLuc BxPC-3 cells as target cells, Coincubation of 7E3 with rhNRG1 31 -ECD (to mimic NRG1 expressed by CAFs) strongly increased ADCC of shLuc BXPC3 cells compared to 7E3 alone. Similar results were obtained with trastuzumab (positive control) (Figure 2D). Upon HER3 silencing, ADCC was not induced by incubation with 7E3, with or without rhNRG1 1 1-ECD. Thus, 7E3 bound to NRG1 Ig-like domain pre complexed with HER3 favors ADCC in pancreatic cancer cells.

3.3. 7E3 blocks NRG1-mediated HER3 signaling and downstream AKT/MAPK phosphorylation, and promotes HER3 downregulation in pancreatic cancer cells As expected, incubation of BXPC-3 and MCF7 cells with rhNRG1 $\beta 1-E C D$ induced phosphorylation of HER3 and of the downstream AKT and MAPK kinases (Figure 3A). This effect was inhibited by 7E3, in 
a dose-dependent manner. Similarly, CM from NRG1-expressing BxPC-3 cells induced HER3, AKT and MAPK phosphorylation in MCF7 breast cancer cells (HER3-expressing but not NRG1) (Supplementary Figure 2A). This effect was blocked by 7E3 demonstrating 7E3 inhibitory effect on NRG1 secreted by cancer cells. Moreover, 7E3 inhibited NRG1-mediated HER4 phosphorylation in IGROV-1 ovarian cancer cells (HER3-negative and HER4-positive) (Figure 3B).

To test whether 7E3 internalization mediated HER3 downregulation in pancreatic cancer cells, BxPC-3 cells were incubated with 7E3 and rhNRG1 $\beta 1-E C D$ at different time points. Co-incubation with 7E3 and rhNRG1 $\beta 1-E C D$ led to antibody binding and internalization that started at $30 \mathrm{~min}$ and peaked at $60 \mathrm{~min}$ at $37^{\circ} \mathrm{C}$ (Figure $3 \mathrm{C}$ ). Conversely, antibody internalization was abrogated at $4^{\circ} \mathrm{C}$. This was confirmed by immunofluorescence analysis after a 60min-incubation with fluorescein-labeled 7E3 (Figure $3 C$ ). Moreover, co-incubation with 7E3 and rhNRG1 $\beta 1$-ECD induced HER3 downregulation in BxPC-3 cells from 10h until 48h (end of the experiment) (Figure 3D).

Here we demonstrated that 7E3 acts by inhibiting HER3 activity and by directly down regulating HER3 expression.

\subsection{E3 inhibits viability, growth and migration of pancreatic cancer cells}

As NRG1 plays a role in cell proliferation, the viability of HPAC and BxPC-3 cells was assessed after co-incubation with 7E3 and rhNRG1 $\beta 1-E C D$, in 2D-cell monolayer cultures (Figure 4A). 7E3 significantly reduced cancer cell viability (between $7 \%$ and $35 \%$ of inhibition) in a dose-dependent manner. Moreover, $100 \mu \mathrm{g} / \mathrm{ml}$ 7E3 alone also reduced by $20 \%$ cell viability of NRG1-positive BxPC-3 cells (Supplementary Figure 2A). The IR antibody did not affect cell viability in any of these experimental conditions. In 3D-cell cultures (Figure 4B), co-incubation with rhNRG1 $\beta 1$-ECD and 7E3 strongly inhibited spheroid growth by about $67 \%$ compared with rhNRG1 $\beta 1-E C D$ alone, as indicated by the reduction of the calcein-positive spheroid area. In wound-healing assays (Figure 4C), exposure of BxPC-3 and HPAC cells to rhNRG1 $\beta 1-E C D$ after wounding increased cell migration in comparison with untreated cells, resulting in the complete wound closure at $48 \mathrm{~h}$ post-wound. Conversely, coincubation with rhNRG1 $\beta 1-E C D$ and 10 or $100 \mu \mathrm{g} / \mathrm{ml}$ of $7 \mathrm{E} 3$, but not with IR antibody, strongly inhibited cell migration and wound healing (Figure 4C).

\subsection{E3 reduces pancreatic tumor growth in mice}


The in vivo efficacy of 7E3 was evaluated in mice xenografted subcutaneously with BxPC-3 cells (NRG1-positive) (Figure 4D). Injection of 7E3 significantly reduced tumor growth compared with the IR antibody (control) $(p=0.020)$. As pancreatic cancer is characterized by poor vascularization, dense microenvironment and reduced drug penetration, the in vivo effect of 7E3 was also studied in an orthotopic pancreatic cancer model (Figure 4E). One week after injection in mice of BxPC-3-Luc cells, the pancreas bioluminescence signal (to follow cancer cell growth) was measured, and then mice were treated with 7E3 or IR antibody (control). The bioluminescence signal remained significantly lower in all 7E3-treated mice compared with controls $(p=0.047)$ (Figure 4E). At day 48 post-graft, bioluminescence was still very low in 7E3-treated mice in comparison with control $(p=0.0404)$ (supplementary Figure 2C). These results demonstrated that 7E3 slows down the growth of NRG1positive pancreatic tumors. Inhibition of AKT and MAPK phosphorylation was observed by Western blot analysis in 7E3 treated subcutaneous tumors in contrast to control tumors (Figure 4F).

3.6. 7E3 induces pancreatic CAF lysis in the presence of hPBMC and inhibits pancreatic cancer cell proliferation promoted by CAFs secreted NRG1

To assess 7E3 effect on pancreatic epithelial cancer cells associated with the surrounding cells, primary CAFs isolated from six human PDAC specimens (Figure 1D) were used. 7E3 could bind to CAFs, as indicated by immunofluorescence analysis of CAF11 and CAF12 cultures (Figure 5A), consistent with NRG1 expression by these CAFs (Figure 1D). Incubation of BxPC-3 cells with CM from CAF11 and CAF12 (CAF-CM) strongly induced HER3 phosphorylation that was inhibited by 7E3, but not the IR antibody (Figure 5B). Similar results were obtained with CAF3, 4, 5 and 6 (Supplementary Figure $3 \mathrm{~A}$ ). Incubation of CAF12 with hPBMC and 7E3, but not the IR antibody, induced ADCC (Figure 5C), albeit weakly, probably due to dynamic NRG1 cleavage at the cell surface by metalloproteinases [17]. Moreover, different CAF-CMs increased BxPC-3 cell viability in 2Dmonolayer culture, compared with cells incubated with medium alone (with 1\% FCS) (Figure 5D and Supplementary Figure 3B). Addition of 7E3, but not of the IR antibody, decreased significantly this effect ( $p<0.001$ for CAF5, 6 and 11-CM), except in BxPC-3 cells incubated with CAF8-CM that was recovered from the NRG1-negative CAF8 culture (Figure 1D). Finally, bioluminescence measures in HPAC-Luc cells co-cultured with CAF11 in a 3D culture system (Figure 5E) showed that incubation with 7E3, but not the IR antibody, reduced HPAC-Luc cell viability in a dose-dependent manner. 
3.7. 7E3 inhibits BxPC-3 tumor growth in nude mice after orthotopic co-injection of BxPC-3 cells and CAFs

To reconstitute in vivo the human pancreatic tumor microenvironment, NRG1-positive BxPC-3 cells and NRG1-positive CAF11 cells (1:2 ratio) were co-xenografted in the pancreas of mice and tumor growth was followed by ultrasonography. In this orthotopic mouse model, 7E3 treatment significantly reduced the growth of reconstituted CAF stroma/BxPC-3 tumors (Figure 6A, supplementary figure 4A) compared with controls (no treatment) $(p=0.003)$. This result was confirmed by the finding that at day 60 (end of the experiment), the mean tumor weight was 44\% lower in 7E3-treated mice than in controls $(p=0.032$ ) (Figure $6 B$ ). IHC analysis of tumors shown the presence of $\alpha$ SMA positive fibroblasts (marker of activated CAF) in tumors and an increased expression of cleaved caspase 3 (in tumor cells), a marker of apoptosis, whereas KI67 index (marker of proliferation) was unchanged (Supplementary Figure 4B) in the antibody treatment tumors vs control (Figure 6C). 


\section{DISCUSSION}

The 7E3 antibody blocked NRG1-dependent tumor cell growth by decreasing HER3 activity and expression level and promoting ADCC activation against tumors cells and micro-environment. This mechanism can contribute to the therapeutic effect observed in mice and can be explained by its original binding. Indeed, our antibody exhibited a high degree of specificity and affinity for NRG1 IgGlike domain, and did not prevent the NRG1 binding to HER3. This explains 7E3 ability to target NRG1 already linked to its receptor and to induce ADCC. This binding feature has never been described and is completely different from the one displayed by other anti-NRG1 antibodies, which are mostly directed to the EGF-like domain and only act by ligand trapping [29]. Ligand trapping has already been evaluated and validated in the clinic in colorectal, lung and breast cancer with the anti-VEGF antibody bevacizumab (30). Pre-clinical projects which aimed at targeting with antibodies other EGFR ligands, such as HB-EGF, TGF $\alpha$ and amphiregulin [31, 32], only proposed a strategy of ligand sequestration, without affecting ligand/receptor complexes as we demonstrated in this study.

The pernicious ability of pancreatic cancer cells to collaborate with the stroma to access resources, such as growth factors and metabolites, is described in numerous studies. Here, we demonstrate how the resulting tumor growth can be efficiently reduced by disturbing the crosstalk between pancreatic tumor cells and CAFs with our anti-NRG1 antibody 7E3. Moreover, 7E3 decreases the viability of NRG1-positive pancreatic cancer cells also in conditions where NRG1 is secreted by the stroma compartment, for instance CAFs.

Our antibody inhibited tumor growth in a more relevant model, in which luciferase-positive BxPC-3 cells were grafted in the pancreas of athymic mice. Despite a weak accessibility of tumors, 7E3 antibody delays significantly their growth. Interestingly, in an orthotopic co-injection of BxPC-3 and CAFs models, our data clearly show that treatment with 7E3 inhibits tumor growth despite the enhanced aggressiveness of this model. It is indeed notable that co-injection of BxPC-3 and CAFs growth faster than cancer cell alone. These preclinical data are the first to describe in pancreatic cancer the therapeutic effect of targeting a growth factor expressed both in tumor cells and in microenvironment (cancer associated fibroblast). The therapeutic efficiency of our 7E3 antibody used alone to delay tumor growth is comparable to earlier studies reported with Trap-Fc molecules or monoclonal antibodies [33]. Finally, wound-healing assays showed that 7E3 reduces BxPC-3 and HPAC cell migration. Although additional studies are needed to confirm 7E3 therapeutic effect in metastatic 
pancreatic cancer, an impact on epithelial-mesenchymal transition is especially suitable, since most pancreatic patients present with a metastatic disease at diagnosis [34, 35].

NRG1 is the main HER3 ligand and promotes HER3/HER2 or HER3/EGFR dimerization, leading to the activation of PI3K/AKT and MAPK/ERK signaling pathways. Although we previously showed the interest to target HER2/HER3 dimers and HER3 in pancreatic cancer (36), the response rate to kinase inhibitors or monoclonal antibodies blocking HER signaling remains limited to weeks, before undergoing resistance process [37]. Actually, clinical treatments combining chemotherapy and targeted therapies, such as erlotinib, provide no or modest benefit since patients rapidly acquire resistance. Several lines of evidence indicate the benefit to use an anti-NRG1 antibody such as 7E3 in this context to bypass this endless issue. First, the complex crosstalk between stromal components and tumor cells could have contributed to the failure of several clinical trials, particularly in pancreatic cancer that is characterized by a strong stromal component [37]. Second, another possible mechanism of chemotherapy resistance is the stimulation of the ErbB/HER or Notch pathways through the upregulation of metalloproteinase-mediated cleavage of transmembrane ligands such as HER's ligands [38-43]. Finally, in other pathologies, acquired NRG1 expression also could drive resistance to targeted therapies, such as anti-HER3 antibodies in non-small cell lung cancer (NSCLC) [44, 45], cetuximab or vemurafenib in colorectal cancer [46, 47], or lapatinib in breast cancer [48].

Knowing that the epitope of 7E3 is found in murine type I and II NRG1 sequences, we can deduce that 7E3 can target the murine NRG1. No adverse effect on normal tissues of our anti-NRG1 antibody in the mouse models was observed. On the basis of its mechanisms of action, we can expect a favorable toxicity profile, as demonstrated for molecules targeting the NRG1 pathway, previously used in clinical trials [49]. Phase 1 trials have shown that anti-HER3 agents are mainly efficient in patients with NRG1-activated tumors. Thus, combining HER3-targeted treatments with our anti-NRG1 antibody might increase the therapeutic index in ligand-activated cancers. Based on a previous report showing the potential of combining mutually non-competitive antibodies (against different epitopes from the same receptor), the association of 7E3 with an anti-HER3 antibody could be a promising approach [50]. Eventually, considering the potential effect of combination therapies in pancreatic cancer treatment, studies on the effect of combining 7E3 with chemotherapy agents, such as gemcitabine or FOLFIRINOX, could pave the way for the development of 7E3-based treatment strategies for PDAC. 
ACKNOWLEDGMENTS.

We thank S. Bousquié, for technical assistance and N. Robin for providing pancreatic tumors. We thank the Montpellier RIO Imaging and the RHEM histology facilities. 


\section{REFERENCES}

[1] A. Vincent, J. Herman, R. Schulick, RH. Hruban, M. Goggins, Pancreatic cancer, Lancet 9791 (2011) 607-20.

[2] L. Rahib, B.D. Smith, R. Aizenberg, A.B. Rosenzweig, J.M. Fleshman, L.M. Matrisian, Projecting cancer incidence and deaths to 2030: the unexpected burden of thyroid, liver, and pancreas cancers in the United States, Cancer Res. 11 (2014) 2913-21.

[3] O. De Wever, M. Mareel, Role of tissue stroma in cancer cell invasion, J. Pathol. 4 (2003) 429-47.

[4] R. Kalluri, The biology and function of fibroblasts in cancer, Nat. Rev. Cancer 9 (2016) 582-98.

[5] K.P. Olive, M.A. Jacobetz, C.J. Davidson, A. Gopinathan, D. McIntyre, D. Honess et al., Inhibition of Hedgehog signaling enhances delivery of chemotherapy in a mouse model of pancreatic cancer, Science 5933 (2009) 1457-61.

[6] S.R. Hingorani, W.P Harris, J.T. Beck, B.A Berdov, S.A. Wagner, E.M. Pshevlotsky et al., Phase lb study of PEGylated recombinant human hyaluronidase and gemcitabine in patients with advanced pancreatic cancer, Clin. Cancer Res. 12 (2016) 2848-54.

[7] M.F. Bijlsma, H.W. Van Laarhoven, The conflicting roles of tumor stroma in pancreatic cancer and their contribution to the failure of clinical trials: a systematic review and critical appraisal. Cancer Metastasis Rev. 1 (2015) 97-114.

[8] J.J. Lee, R.M. Perera, H. Wang, D.C. Wu, X.S. Liu, S. Han et al., Stromal response to Hedgehog signaling restrains pancreatic cancer progression, Proc. Natl. Acad. Sci. U. S. A. 30 (2014) 3091-10.

[9] B.C. Özdemir, T. Pentcheva-Hoang, J.L. Carstens, X. Zheng, C.C. Wu, T.R. Simpson et al., Depletion of carcinoma-associated fibroblasts and fibrosis induces immunosuppression and accelerates pancreas cancer with reduced survival, Cancer Cell. 6 (2014) 719-34.

[10] R. Kalluri, The biology and function of fibroblasts in cancer, Nat. Rev. Cancer 9 (2016) 582-98.

[11] D. Öhlund, E. Elyada, D. Tuveson, Fibroblast heterogeneity in the cancer wound, J. Exp. Med. 8 (2014) 1503-23.

[12] C.S. Crovello, C. Lai, L.C. Cantley, K.L. Carraway, Differential signaling by the epidermal growth factor-like growth factors neuregulin-1 and neuregulin-2, J. Biol. Chem. 41 (1998) 26954-61.

[13] J.C Montero, R. Rodríguez-Barrueco, A. Ocaña, E. Díaz-Rodríguez, A. Esparís-Ogando, A. Pandiella, Neuregulins and cancer, Clin. Cancer Res. 11 (2008) 3237-4.

[14] G. Qian, N. Jiang, D. Wang, S. Newman, S. Kim et al., Heregulin and HER3 are prognostic biomarkers in oropharyngeal squamous cell carcinoma, Cancer 20 (2015) 3600-11.

[15] A. Kolb, J. Kleeff, N. Arnold, N.A. Giese, T. Giese, M. Korc et al., Expression and differential signaling of heregulins in pancreatic cancer cells, Int. J. Cancer 3 (2007) 514-23.

[16] M.S. Tsai, L.A. Shamon-Taylor, I. Mehmi, C.K. Tang, R. Lupu, Blockage of heregulin expression inhibits tumorigenicity and metastasis of breast cancer, Oncogene 5 (2003) 761-8.

[17] H. Lee, R.W. Akita, M.X. Sliwkowski, N.J. Maihle, A naturally occurring secreted human ErbB3 receptor isoform inhibits heregulin-stimulated activation of ErbB2, ErbB3, and ErbB4, Cancer Res. 11 (2001) 4467-73.

[18] H. Kawakami, I. Okamoto, K. Yonesaka, K. Okamoto, K. Shibata, Y. Shinkai et al., The anti-HER3 antibody patritumab abrogates cetuximab resistance mediated by heregulin in colorectal cancer cells, Oncotarget 23 (2014) 11847-56. 
[19] H. Friess, Y. Yamanaka, M.S. Kobrin, D.A. Do, M.W. Büchler, M. Korc, Enhanced erbB-3 expression in human pancreatic cancer correlates with tumor progression, Clin. Cancer. Res. 1 (1995) $1413-1420$.

[20] J.S. Liles, J.P. Arnoletti, C.W.D. Tzeng, J.H. Howard, A.V. Kossenkov, P. Kulesza et al., ErbB3 expression promotes tumorigenesis in pancreatic adenocarcinoma, Cancer Biol. Ther. 10 (2010) 555563.

[21] Y. Yamanaka, H. Friess, M.S. Kobrin, M. Buchler, H.G. Beger, M. Korc, Coexpression of epidermal growth factor receptor and ligands in human pancreatic cancer is associated with enhanced tumor aggressiveness, Anticancer Res. 13 (1993) 565-569.

[22] H. Safran, M. Steinhoff, S. Mangray, R. Rathore, T.C. King, L. Chai et al., Overexpression of the HER-2/neu oncogene in pancreatic adenocarcinoma, Am. J. Clin. Oncol. 24 (2001) 496-499.

[23] G. Thomas, T. Chardès, N. Gaborit, C. Mollevi, W. Leconet, B. Robert et al., HER3 as biomarker and therapeutic target in pancreatic cancer: new insights in pertuzumab therapy in preclinical models, Oncotarget 16 (2014) 7138-48.

[24] N. Gaborit, C. Larbouret, J. Vallaghe, F. Peyrusson, C. Bascoul-Mollevi, E. Crapez et al., A Timeresolved fluorescence resonance energy transfer (TR-FRET) to analyze the disruption of EGFR/HER2 dimers: a new method to evaluate the efficiency of targeted therapy using monoclonal antibodies, J. Biol. Chem. 13 (2011) 11337-4.

[25] Y. Lazrek, O. Dubreuil, V. Garambois, N. Gaborit, C. Larbouret, C. Le Clorennec et al., Anti-HER3 domain 1 and 3 antibodies reduce tumor growth by hindering HER2/HER3 dimerization and AKTinduced MDM2, XIAP, and FoxO1 phosphorylation, Neoplasia 3 (2013).

[26] C. Duluc, S. Moatassim-Billah, M. Chalabi-Dchar, A. Perraud, R. Samain, F. Breibach et al., Pharmacological targeting of the protein synthesis mTOR/4E-BP1 pathway in cancer-associated fibroblasts abrogates pancreatic tumour chemoresistance, EMBO Mol. Med. 6 (2015) 735-53.

[27] W. Leconet, C. Larbouret, T. Chardès, G. Thomas, M. Neiveyans, M. Busson M et al., Preclinical validation of $\mathrm{AXL}$ receptor as a target for antibody-based pancreatic cancer immunotherapy, Oncogene 47 (2014) 5405-14.

[28] W. Leconet, M. Chentouf, S. du Manoir, A. Chevalier, S. Sirvent, I. Aït-Arsa et al., Therapeutic Activity of Anti-AXL Antibody against Triple-Negative Breast Cancer Patient-Derived Xenografts and Metastasis, Clin. Cancer Res. 11 (2017) 2806-2816.

[29] G.V. Hegde, C.C. De la Cruz, C. Chiu, N. Alag, G. Schaefer, L. Crocker et al., Blocking NRG1 and other ligand-mediated Her4 signaling enhances the magnitude and duration of the chemotherapeutic response of non-small cell lung cancer, Sci. Transl. Med. 171 (2013) 171ra18.

[30] N. Ferrara, A.P. Adamis, Ten years of anti-vascular endothelial growth factor therapy, Nat. Rev. Drug. Discov. 6 (2016) 385-403.

[31] M. Lindzen, S. Lavi, O. Leitner, Y. Yarden, Tailored cancer immunotherapy using combinations of chemotherapy and a mixture of antibodies against EGF-receptor ligands, Proc. Natl. Acad. Sci. U. S. A. 28 (2010) 12559-63.

[32] S. Carvalho, M. Lindzen, M. Lauriola, N. Shirazi, S. Sinha, A. Abdul-Hai et al., An antibody to amphiregulin, an abundant growth factor in patients' fluids, inhibits ovarian tumors, Oncogene 4 (2016) 438-47.

[33] M. Lindzen, S. Carvalho, A. Starr, N. Ben-Chetrit, C.R. Pradeep, W.J. Köstler et al., A recombinant decoy comprising EGFR and ErbB-4 inhibits tumor growth and metastasis, Oncogene 30 (2012) 3505-15.

[34] T. Arumugam, V. Ramachandran, K.F. Fournier, H. Wang, L. Marquis, J.L. Abbruzzese et al., 
Epithelial to mesenchymal transition contributes to drug resistance in pancreatic cancer, Cancer Res. 14 (2009) 5820-8.

[35] A.D. Rhim, E.T. Mirek, N.M. Aiello, A. Maitra, J.M. Bailey, F. McAllister et al., EMT and dissemination precede pancreatic tumor formation, Cell 1-2 (2012) 349-61.

[36] I. Garrido-Laguna, M. Hidalgo, Pancreatic cancer: from state-of-the-art treatments to promising novel therapies, Nat. Rev. Clin. Oncol. 6 (2015) 319-34.

[37] N. Waddell, Whole genomes redefine the mutational landscape of pancreatic cancer, Nature 7540 (2015) 495-501.

[38] C.M. Ardito, C.D. Briggs, H.C. Crawford, Targeting of extracellular proteases required for the progression of pancreatic cancer, Expert Opin. Ther. Targets. 5 (2008) 605-19.

[39] E.T. Sawey, H.C. Crawford, Metalloproteinases and cell fate: Notch just ADAMs anymore, Cell Cycle 5 (2008) 566-9.

[40] U. Schlomann, G. Koller, C. Conrad, T. Ferdous, P. Golfi, A.M. Garcia et al., ADAM8 as a drug target in pancreatic cancer, Nat. Commun. 6 (2008) 6175.

[41] N. Woods, J. Trevino, D. Coppola, S. Chellappan, S. Yang, J. Padmanabhan, Fendiline inhibits proliferation and invasion of pancreatic cancer cells by interfering with ADAM10 activation and $\beta$ catenin signaling, Oncotarget 34 (2015) 35931-48.

[42] J.N. Kyula, S. Van Schaeybroeck, J. Doherty, C.S. Fenning, D.B. Longley, P.G. Johnston, Chemotherapy-induced activation of ADAM-17: a novel mechanism of drug resistance in colorectal cancer, Clin. Cancer Res. 13 (2010) 3378-89.

[43] S. Van Schaeybroeck, J.N. Kyula, A. Fenton, C.S. Fenning, T. Sasazuki, S. Shirasawa et al., Oncogenic Kras promotes chemotherapy-induced growth factor shedding via ADAM17, Cancer Res. 3 (2011) 1071-80.

[44] J. Mendell, D.J. Freeman, W. Feng, T. Hettmann, M. Schneider, S. Blum et al., Clinical translation and validation of a predictive biomarker for patritumab, an anti-human epidermal growth factor receptor 3 (HER3) monoclonal antibody in patients with advanced non-small cell lung cancer, EBioMedicine 3 (2015) 264-71.

[45] K. Yonesaka, K. Kudo, S. Nishida, T. Takahama, T. Iwasa, T. Yoshida et al., The pan-HER family tyrosine kinase inhibitor afatinib overcomes HER3 ligand heregulin-mediated resistance to EGFR inhibitors in non-small cell lung cancer, Oncotarget 32 (2015) 33602-11.

[46] H. Kawakami, I. Okamoto, K. Yonesaka, K. Okamoto, K. Shibata, Y. Shinkai et al., The anti-HER3 antibody patritumab abrogates cetuximab resistance mediated by heregulin in colorectal cancer cells, Oncotarget 23 (2014) 11847-56.

[47] P.R. Prasetyanti, E. Capone, D. Barcaroli, D. D'Agostino, S. Volpe, A. Benfante et al., ErbB-3 activation by NRG-1 $\beta$ sustains growth and promotes vemurafenib resistance in BRAF-V600E colon cancer stem cells (CSCs), Oncotarget 19 (2015) 16902-11.

[48] W.Y. Leung, I. Roxanis, H. Sheldon, F. M. Buffa, J.L. Li, A.L. Harris et al., Combining lapatinib and pertuzumab to overcome lapatinib resistance due to NRG1-mediated signalling in HER2-amplified breast cancer, Oncotarget 8 (2015) 5678-94.

[49] J.M. Mota, K.A. Collier, R.L.B. Costa, T. Taxter, A. Kalyan, C.A. Leite et al., A comprehensive review of heregulins, HER3, and HER4 as potential therapeutic targets in cancer, Oncotarget 51 (2017) 89284-89306.

[50] D.A. Ferraro, N. Gaborit, R. Maron, H. Cohen-Dvashi, Z. Porat, F Pareja et al., Inhibition of triplenegative breast cancer models by combinations of antibodies to EGFR, Proc. Natl. Acad. Sci. U. S. A. 
5 (2013) 1815-20. 


\section{FIGURE LEGENDS}

Figure 1. NRG1 expression in pancreatic cancer cells and cancer-associated fibroblasts (CAFs).

(A) RT-qPCR analysis of NRG1 mRNA levels in pancreatic tumor samples from patients who underwent surgical resection. Results are expressed as mRNA Arbitrary Units and normalized to the expression of the housekeeping gene HPRT. (B) NRG1 11 expression analysis by RT-qPCR and ELISA in the pancreatic cancer cells lines of AsPC-1, BxPC-3, CFPAC, HPAC, Mia-PaCa-2 and SW1990 and in AsPC-1-NRG1 cells that stably overexpress NRG1 and their conditioned medium. NPC are a mix of three normal pancreatic cells. NPF are normal pancreatic fibroblasts. Results are normalized to the expression of the housekeeping gene HPRT and expressed relatively to the lower cells expressing NRG1 (CFPAC=1). (C) Pro-tumor effect of NRG1 expressed and secreted by AsPC1-NRG1 cells. Proliferation of AsPC-1-NRG1 and AsPC-1-Mock cells was studied by counting cells for 6 days (middle panel). AsPC-1-NRG1 and AsPC-1-Mock cells were xenografted in nude mice. Tumor growth was monitored every week, and at 40 days post-graft mice were sacrificed and tumors weighted (bottom panel). (D) $\alpha$ SMA and vimentin expression by immunofluorescence analysis in CAFs from pancreatic cancer surgical biopsies or normal pancreatic fibroblasts (NPF) (top panels). (E) NRG1 mRNA was quantified by RT-qPCR in CAF cultures. Results are expressed as mRNA Arbitrary Units and normalized to HPRT expression. (F) The level of NRG1 secreted was measured in conditioned medium (CM) from CAF cultures grown in serum-free medium for $48 \mathrm{~h}$ by ELISA assay. These CM was also added to serum-starved BxPC-3 cells for 15 minutes. The total level of phosphorylated HER3 was then measured by Western blotting (bottom panel). $\left({ }^{*} p<0.05 ;{ }^{* *} p<0.01\right.$; $\left.{ }^{* * *} p<0.001\right)$.

Figure 2. Characterization of the Ig-like domain-specific antibody 7E3.

(A) SPR analysis of the binding kinetics between the anti-NRG1 antibody 7E3, rhNRG1 $\beta 1-E C D$ and recombinant human HER3-Fc. HER3-Fc was captured on the sensor chip surface using an antihuman Fc antibody, then 185nM rhNRG1 $\beta 1$-ECD was injected followed by an injection of 200nM of 7E3 antibody. (B) Immunofluorescence detection of the 7E3 antibody on HER3-positive (shLuc) or HER3-silenced shHER3 BxPC-3 cells. Cells were serum-starved and then incubated with increasing concentrations of rhNRG1 $\beta 1-\mathrm{ECD}(1$ to $100 \mathrm{ng} / \mathrm{ml})$ and $20 \mu \mathrm{g} / \mathrm{ml}$ of $7 \mathrm{E} 3$ at $4^{\circ} \mathrm{C}$ for 1 hour. Then, FITCconjugated goat anti-mouse IgGs were added. Anti-HER3 and anti-CEA antibodies were used as controls for HER3 and CEA expression. (C) Alanine scanning analysis to precisely identify 7E3 
binding motif in the three membrane pentadecapeptides that correspond to the identified antibodyimmunoreactive sequences. Each bar represents 7E3 reactivity toward a pentadecapeptide sequence in which the indicated amino acid was substituted by alanine. The mean spot reactivity for each residue was calculated from the results obtained in the three pentadecapeptides using ImageJ.

(D) Evaluation of 7E3-dependent ADCC activity against shHER3 or shLuc BxPC-3 cells by hPBMCs. Cells were first incubated or not with $50 \mathrm{ng} / \mathrm{ml} \mathrm{rhNRG} 1 \beta 1-\mathrm{ECD}$ and/or with $50 \mu \mathrm{g} / \mathrm{ml} 7 \mathrm{E3}$ or with the anti-HER2 antibody trastuzumab (positive control) at $37^{\circ} \mathrm{C}$ for $30 \mathrm{~min}$. Then, cells were incubated with hPBMC $\left(37^{\circ} \mathrm{C}\right)$ at an effector:target ratio of $15: 1$ for $24 \mathrm{~h}$. BxPC-3 cell lysis was evaluated by measuring LDH release by bioluminescence.

Figure 3. The 7E3 antibody inhibits NRG1 $\beta 1$-induced phosphorylation of HER3 and downstream signaling pathways and promotes HER3 downregulation.

(A) BxPC-3 and MCF7 cells were starved for $24 \mathrm{~h}$, and then incubated for $15 \mathrm{~min}$ with $15 \mathrm{ng} / \mathrm{ml}$ rhNRG1 $\beta 1$-EDC and/or 3 to $100 \mu \mathrm{g} / \mathrm{ml} 7 \mathrm{E} 3$ or $100 \mu \mathrm{g} / \mathrm{ml}$ irrelevant antibody (IR). After cell lysis, the expression of phosphorylated and total HER3, AKT and ERK was analyzed by western blotting. (B) 7E3 effect on HER4 phosphorylation was studied by western blotting in IGROV-1 cells following the same protocol as in A. (C) Internalization of 7 E3 in BxPC-3 cells was detected by immunofluorescence. Cells were starved and co-incubated with rhNRG1 $\beta 1$-EDC and either with 7E3 $\left(4^{\circ} \mathrm{C}\right.$ or $\left.37^{\circ} \mathrm{C}\right)$ for different time points and then with FITC-conjugated goat anti-mouse IgGs, or with 7E3 directly labelled with FITC. Control cells were incubated with FITC-conjugated goat anti-mouse IgGs. (D) HER3 expression in BxPC-3 cells was analyzed by Western blotting at different time points after incubation with $100 \mu \mathrm{g} / \mathrm{ml}$ 7E3 or irrelevant antibody (IR) together with $15 \mathrm{ng} / \mathrm{ml} \mathrm{rhNRG} 1 \beta 1$-EDC and was quantified relatively to tubulin levels (lower panels).

Figure 4. The 7E3 antibody inhibits viability, growth and migration of pancreatic cancer cells.

(A) Cell viability of BxPC-3 and HPAC cells was analyzed by using the sulforhodamine B assay. After serum starvation for $24 \mathrm{~h}$, cells were incubated for 5 days with 15 or $10 \mathrm{ng} / \mathrm{ml} \mathrm{rhNRG} 1 \beta 1$-EDC, respectively, and with different concentrations of 7E3 or irrelevant antibody (IR). Results are presented as the percentage of cell viability relative to NRG1 $\beta 1$-treated cells $(=100 \%)$. Each value represents the mean \pm SEM of four experiments. (B) For 3D growth assays, BxPC-3 cells were seeded in Ultra Low Attachment plates to allow spheroid formation. After 10 days of growth in the presence of $50 \mathrm{ng} / \mathrm{ml}$ rhNRG1 $\beta 1$-EDC and 50-100 $\mathrm{g} / \mathrm{ml}$ 7E3 or irrelevant antibody (IR), spheroid cells were labeled with 
calcein and fluorescence was measured with a Celigo Image Cytometer. (C) Wound healing assays using BxPC-3 and HPAC cells. After 24h of serum starvation, cells were wounded and wound healing was monitored in BxPC-3 and HPAC cells left untreated or stimulated for $48 \mathrm{~h}$ with 15 or $10 \mathrm{ng} / \mathrm{ml}$ rhNRG1 $\beta 1-E C D$, respectively, together with 10 or $100 \mu \mathrm{g} / \mathrm{ml}$ of 7E3 when indicated. (D) After BxPC-3 cell xenograft, mice were treated with $10 \mathrm{mg} / \mathrm{kg}$ 7E3 or irrelevant antibody (IR) twice per week for 4 weeks. Results are presented as the mean tumor volume \pm SEM for each group $(n=10$ animal per group). At day 48 , all mice were killed and bioluminescence in pancreas measured. $\left({ }^{*} p<0.05\right.$; $\left.{ }^{* *} p<0.01 ;{ }^{* *} p<0.001\right)$. (E) BxPC-3-Luc cells were injected in the pancreas of nude mice. After 7 days, xenografted animals were treated for 6 weeks. Tumor growth was evaluated by measuring the emitted luminescence once per week after luciferin injection. Bioluminescence intensity $(p / s)$ is presented as a function of treatment duration. (F) 7E3 antibody, but not saline, induced inhibition of MAPK and AKT phosphorylation in BxPC-3 xenograft after 2 weeks of treatment. GAPDH served as loading control.

Figure 5. 7E3 inhibits 2D and 3D pancreatic cancer cell growth induced by pancreatic CAF- secreted NRG1.

(A) Binding of 7E3 to CAFs isolated from PDAC specimens was assessed by immunofluorescence (X40). (B) HER3 phosphorylation in BxPC-3 cells upon incubation with conditioned medium (CM) from the indicated pancreatic CAF cultures without or with $100 \mu \mathrm{g} / \mathrm{ml}$ of $7 \mathrm{E} 3$ or the irrelevant antibody (IR) was analyzed by western blotting. (C) Evaluation of 7E3-dependent ADCC activity against CAFs by hPBMCs. CAFs were incubated or not with $5 \mu \mathrm{g} / \mathrm{ml}$ or $50 \mu \mathrm{g} / \mathrm{ml} 7 \mathrm{E} 3$ or irrelevant antibody (IR) and hPBMC (effector:target ratio of $15: 1)$ for $24 \mathrm{~h}\left(37^{\circ} \mathrm{C}\right)$. CAF lysis was evaluated by measuring LDH release by bioluminescence. (D) After serum starvation for $24 \mathrm{~h}, \mathrm{BxPC}-3$ cells were incubated with CM from CAF5, CAF6, CAF8 and CAF11 without or with $100 \mu \mathrm{g} / \mathrm{ml}$ of $7 \mathrm{E} 3$ or the irrelevant antibody (IR). After 5 days, cell viability was tested with the sulforhodamine B assay $(n=3)$. (E) HPAC cells transfected with luciferase (HPAC-Luc) were co-cultured with CAF11 cells (1/1) in ultra-low attachment plates and incubated with 7E3 or the irrelevant (IR) antibody. After 10 days, HPAC-Luc cell growth was analyzed by bioluminescence. $\left({ }^{*} p<0.05 ;{ }^{* *} p<0.01 ;{ }^{* * *} p<0.001\right)$.

Figure 6. Effect of 7E3 on BxPC-3 tumor growth after co-injection of BxPC-3 cells and CAFs in the pancreas of athymic mice. 
(A) BxPC-3 cells and CAFs (both NRG1-positive) were injected at a 1:2 ratio in the pancreas of athymic mice ( $\mathrm{n}=10$ per group). After 7 days, mice were treated or not (NT) with $10 \mathrm{mg} / \mathrm{kg}$ of 7E3 twice per week for 6 weeks. Tumor volume was measured by ultrasonography. Results are presented as the mean tumor volume for each group. (B) At the end of treatment, tumors were collected and weighed. $\left({ }^{*} p<0.05 ;{ }^{* *} p<0.01 ;{ }^{* *} p<0.001\right)$. (C) Immunohistochemistry analysis shows the presence of $\alpha S M A$ positive fibroblast and an increase of cleaved caspase 3 in 7E3 treated tumors, but not in saline treated controls. 


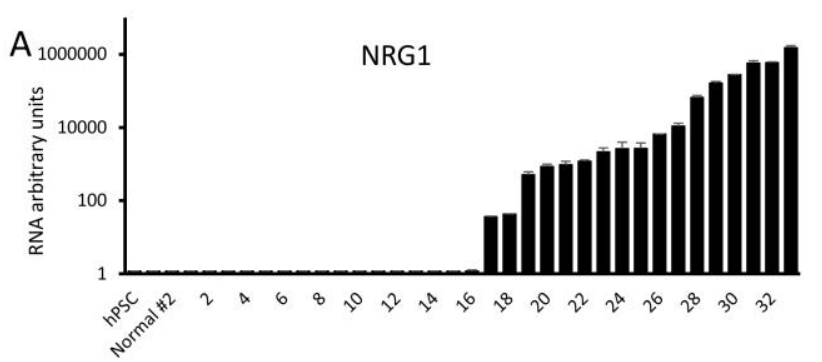

B

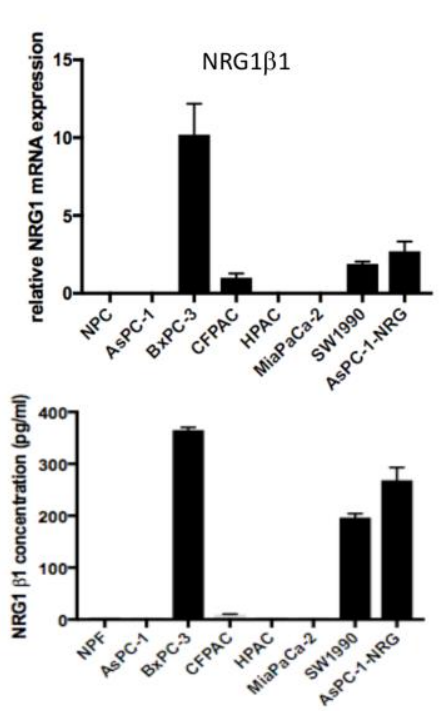

C
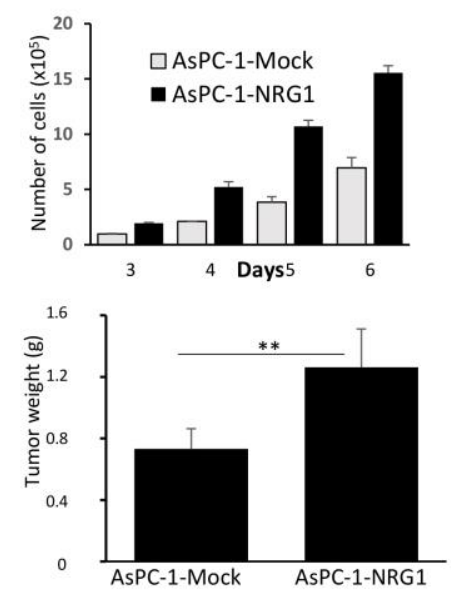
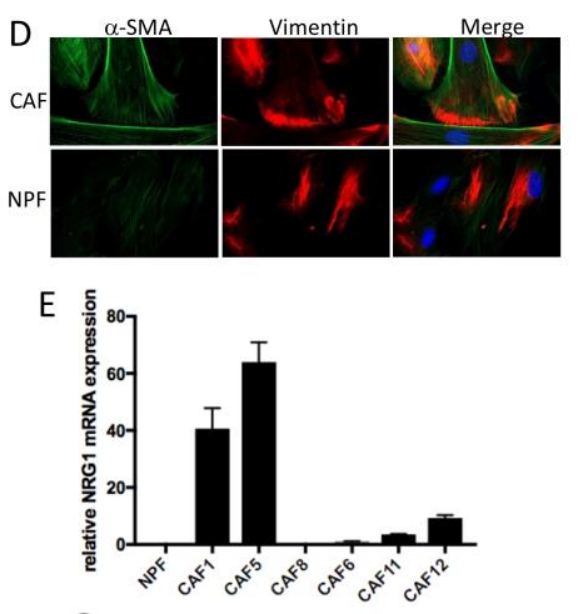

F

Figure 1 

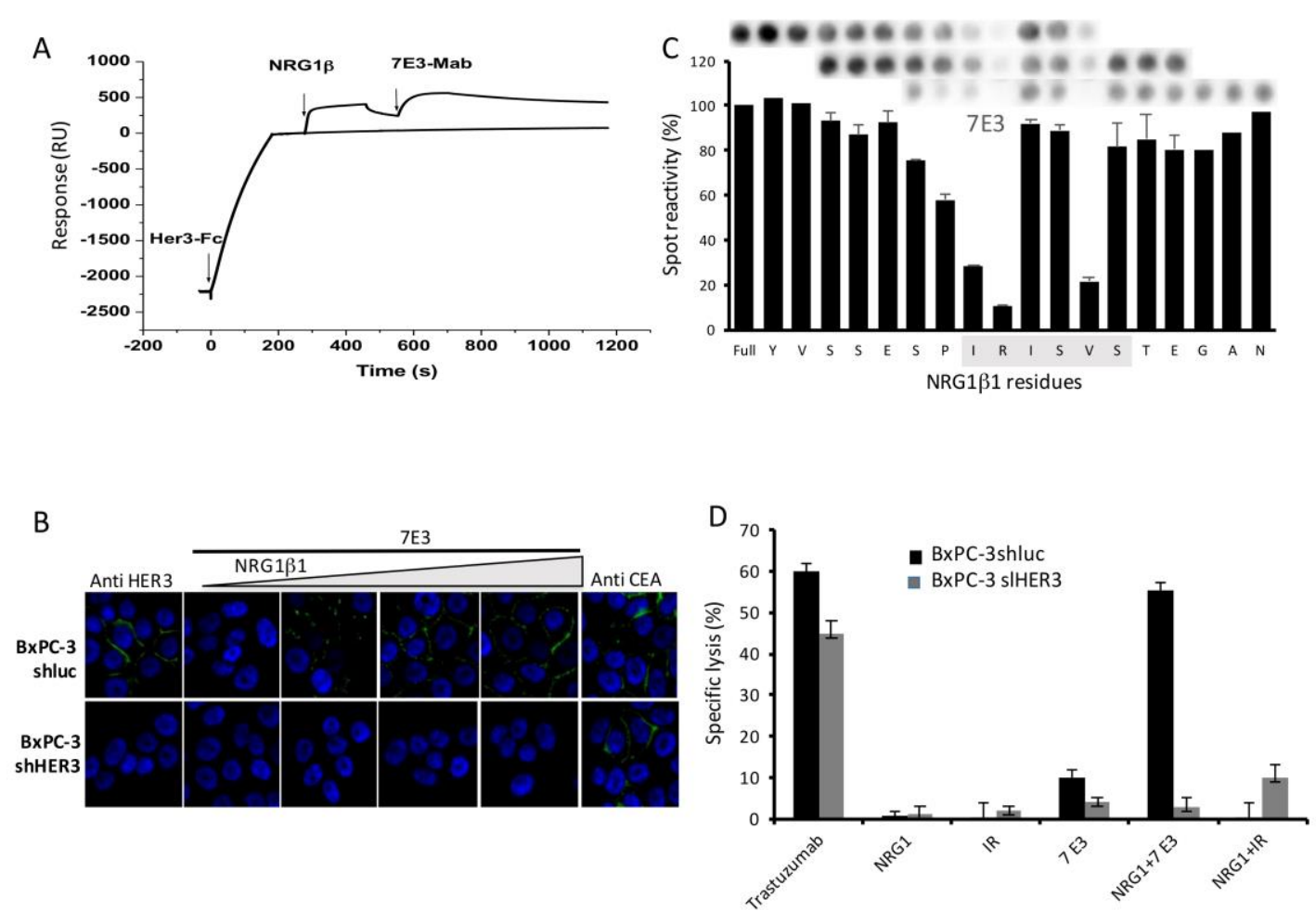

Figure 2 


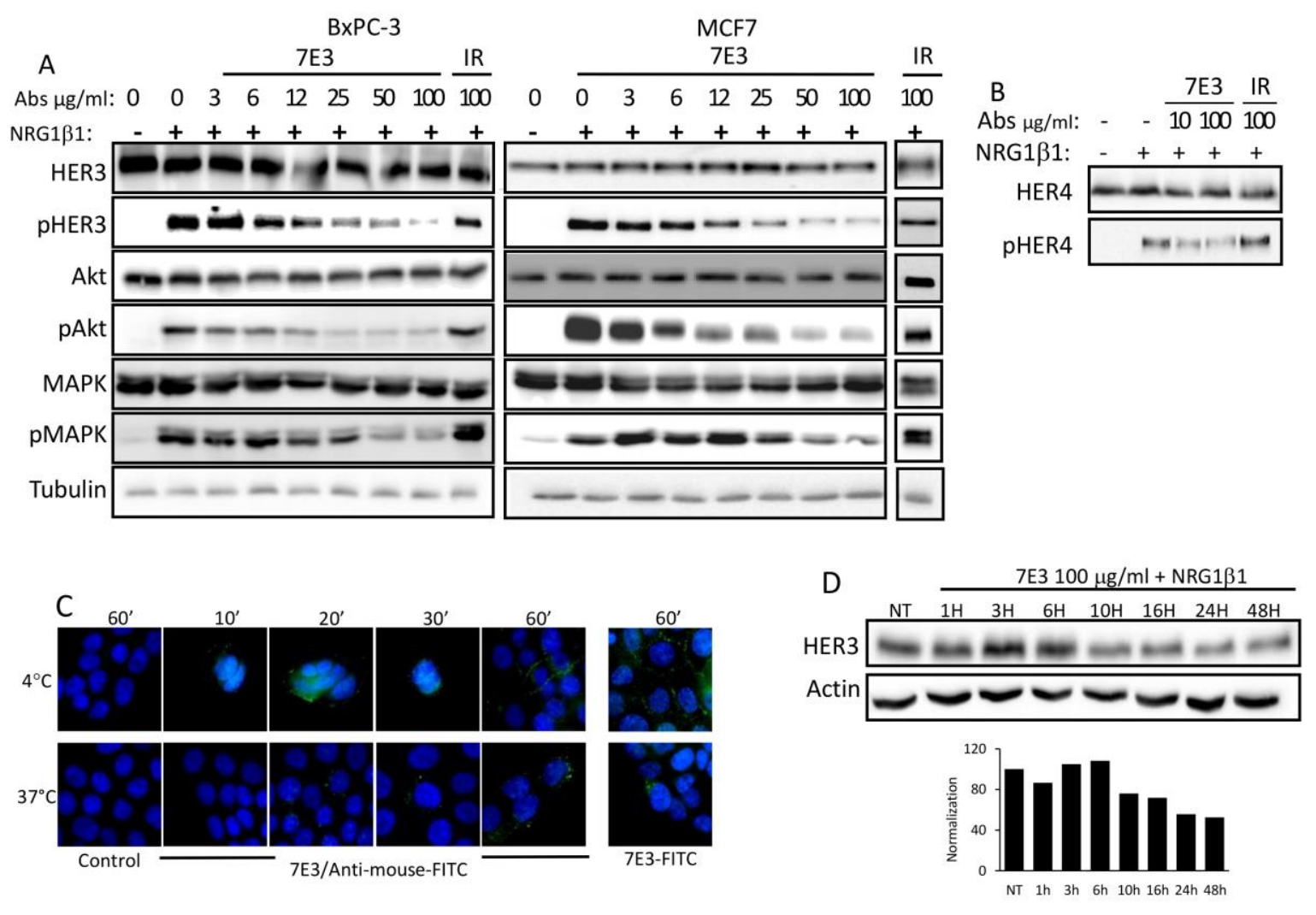

Figure 3 

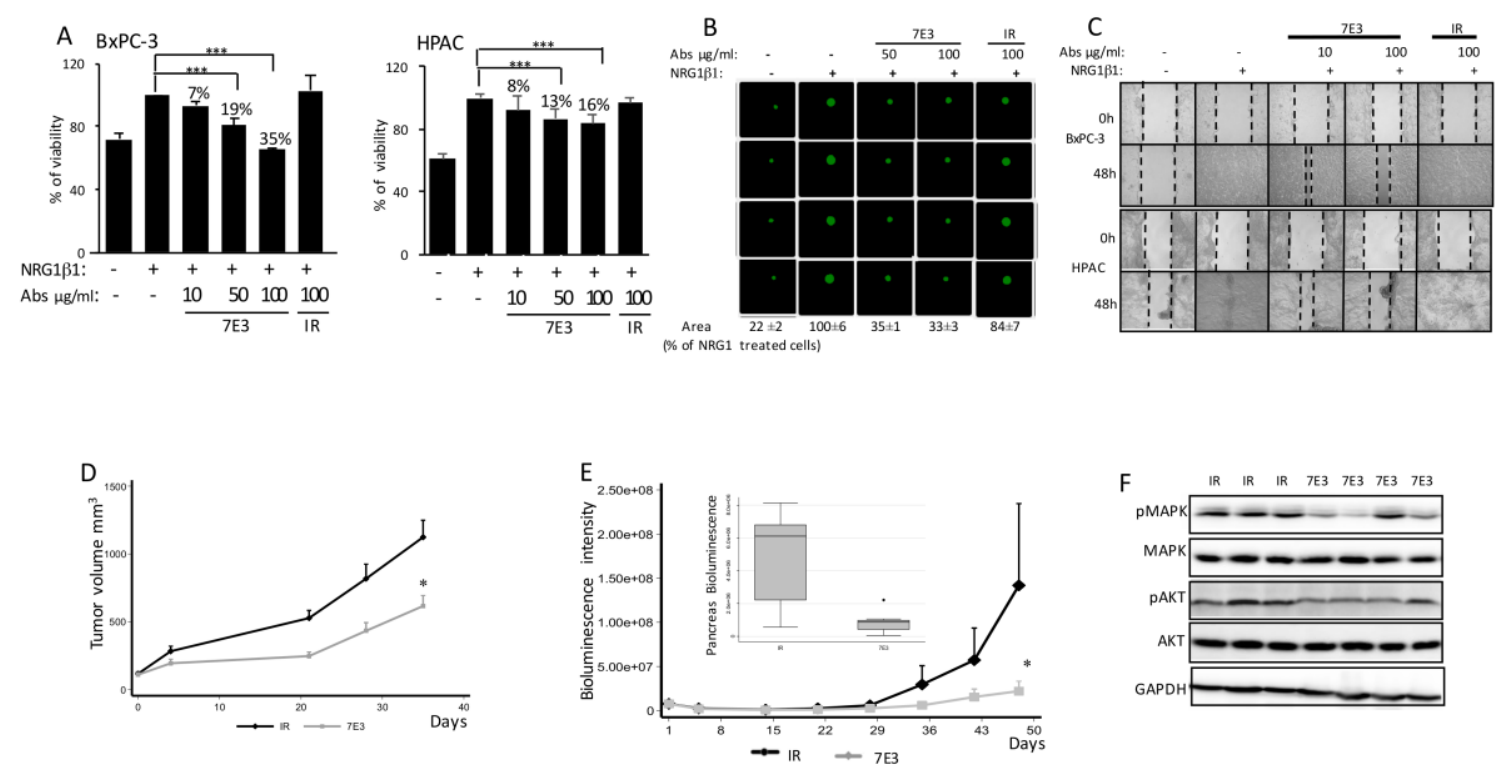

Figure 4 

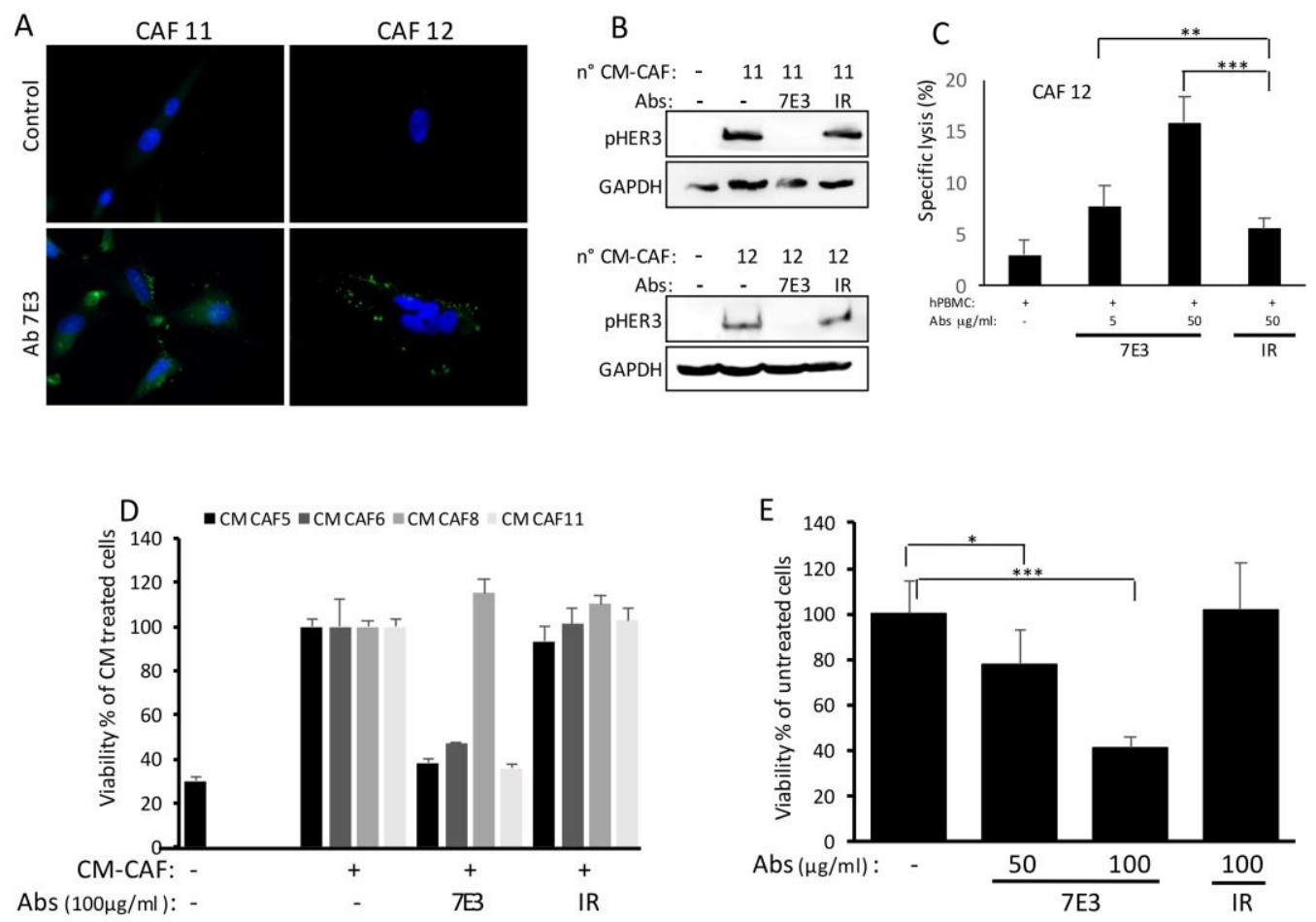

Figure 5 

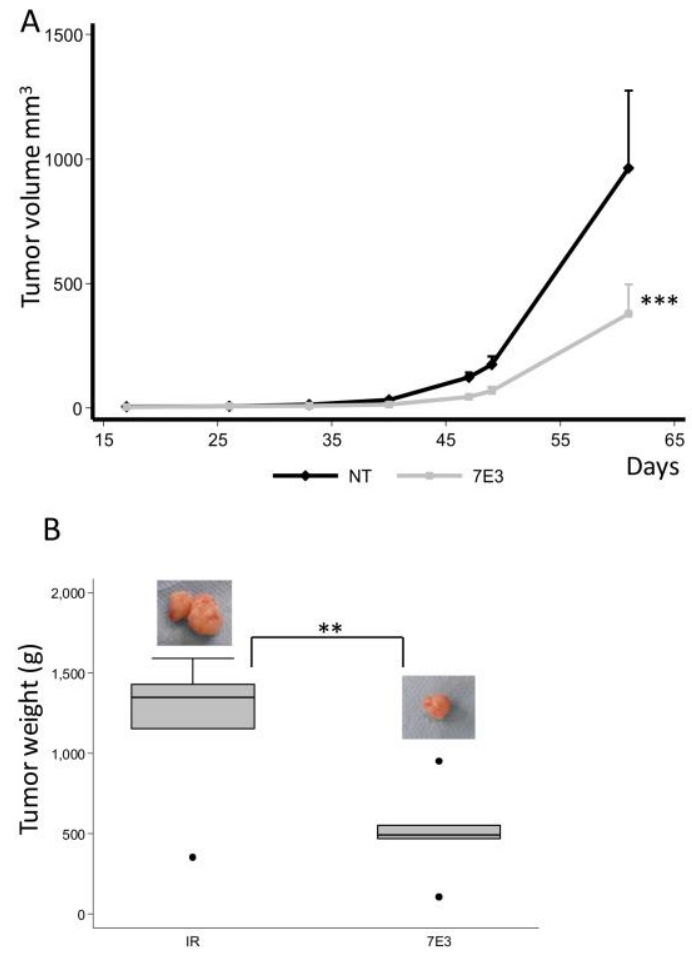
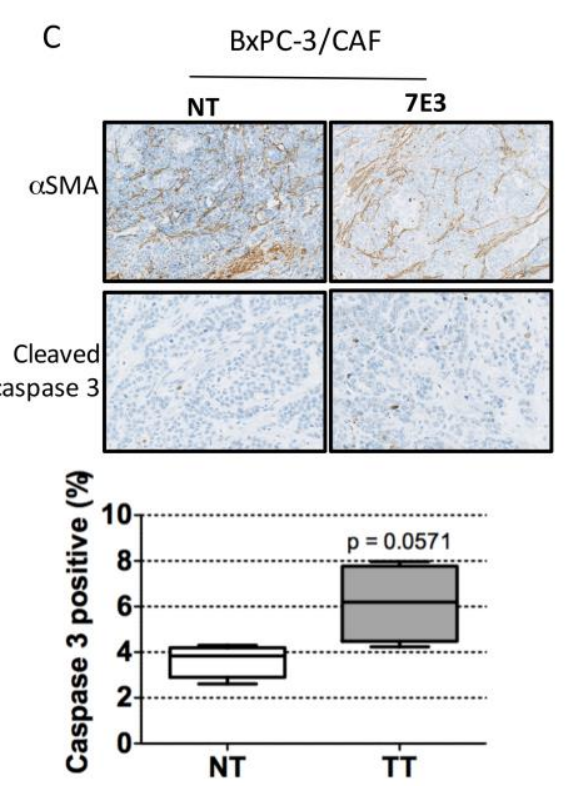

Figure 6 

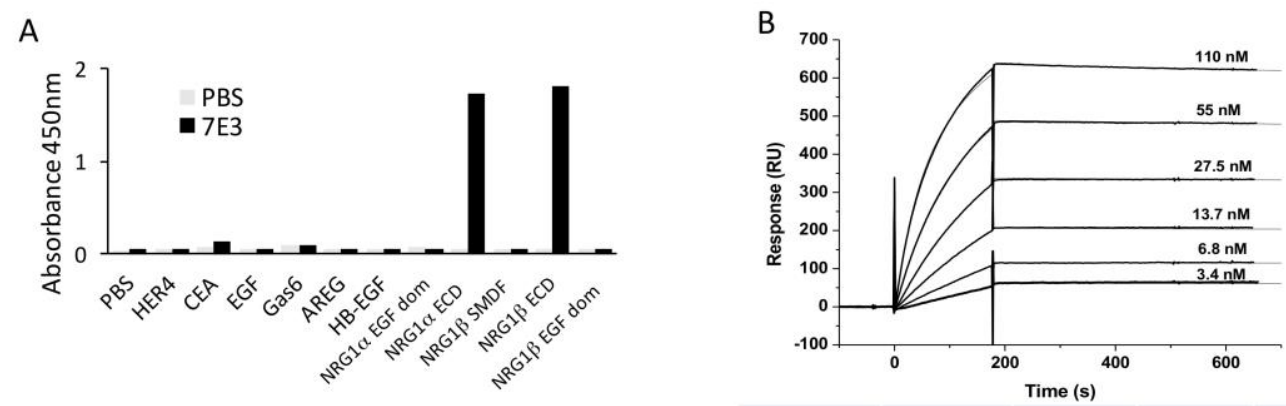

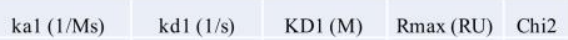

\begin{tabular}{l}
$6.3+/-0.3 \times 10^{4} \quad 6.6+/-0.2 \times 10^{-5} \quad 1.05 \times 10^{9}$ \\
\hline
\end{tabular}

Specificity and affinity of the anti-NRG1 antibody 7E3. (A) Plates coated with proteins were incubated with 7E3. After washing, HRP-conjugated anti-mouse IgG was added and the absorbance read at $450 \mathrm{~nm}$. (B) Affinity measurement of 7E3 using Surface plasmon resonance. 7E3 is coated on the chip and increased concentration of NRG1 is injected in the flow.

\section{Supplemental Figure S1}



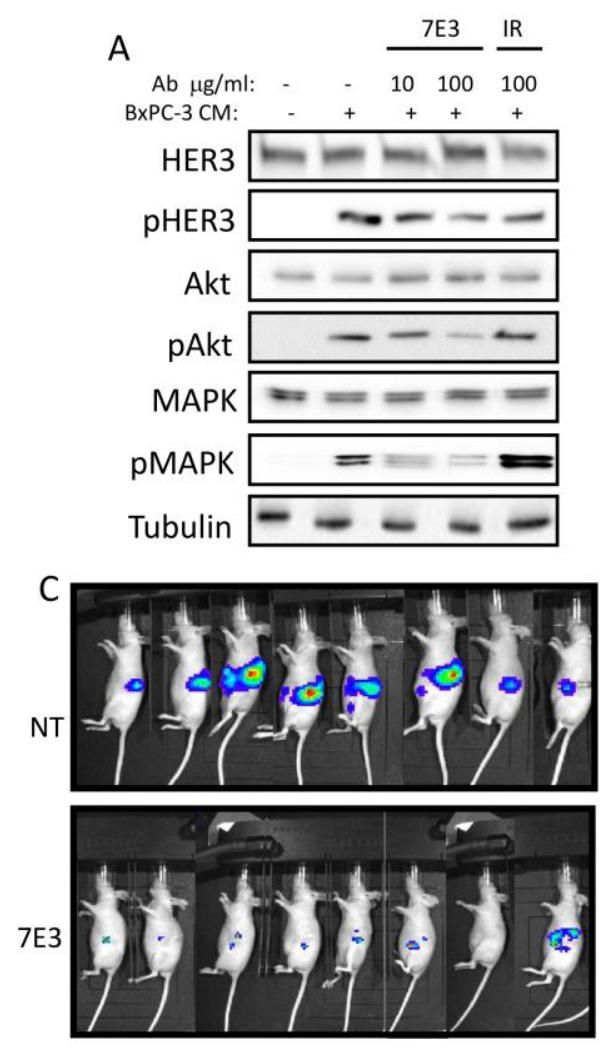

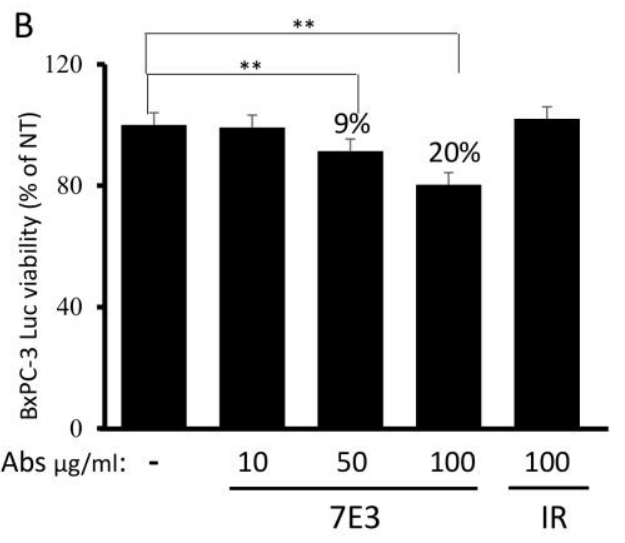

(A) MCF7 were incubated with supernatant of BxPC-3 grown in starved medium for $48 \mathrm{~h}$ with 7E3 or Irrelevant Ab (IR). (B) cell viability of BxPC-3-luc treated with 7E3 or IR. BxPC-3-luc cells were grown in serum free medium and treated with $7 E 3$ or IR Ab for 5 days. (C) bioluminescence image at day 49 corresponding of figure 4E. Tumor growth was evaluated by measuring the emitted luminescence once per week.

Supplemental Figure S2 


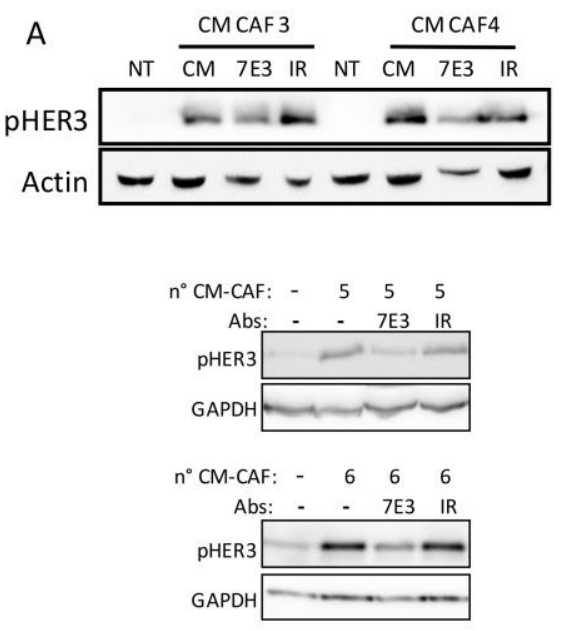

B

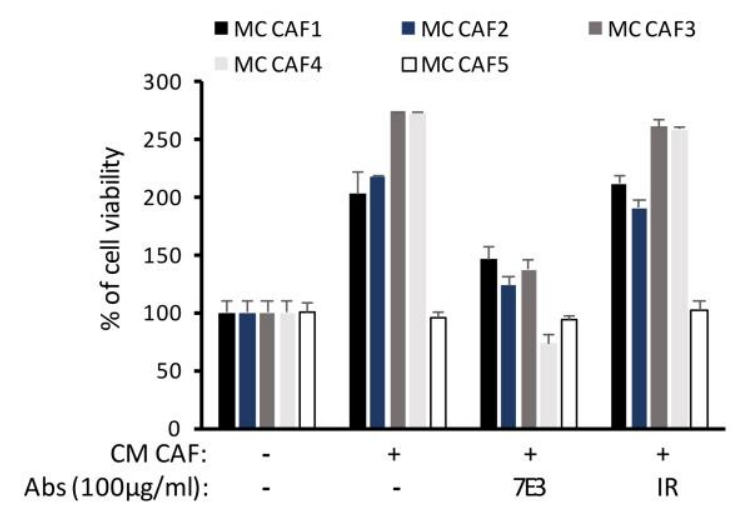

(A) HER3 phosphorylation in BxPC-3 cells upon incubation with conditioned medium (CM) from the indicated pancreatic CAF cultures without or with $7 E 3$ or the irrelevant antibody (IR) was analyzed by Western blotting. (B) After serum starvation for $24 \mathrm{~h}, \mathrm{BxPC}-3$ cells were incubated with indicated $\mathrm{CM}$ without or with 7E3 or the irrelevant antibody (IR). After 5 days, cell viability was tested with the sulforhodamine B assay $(n=3)$.

Supplemental Figure S3 
A
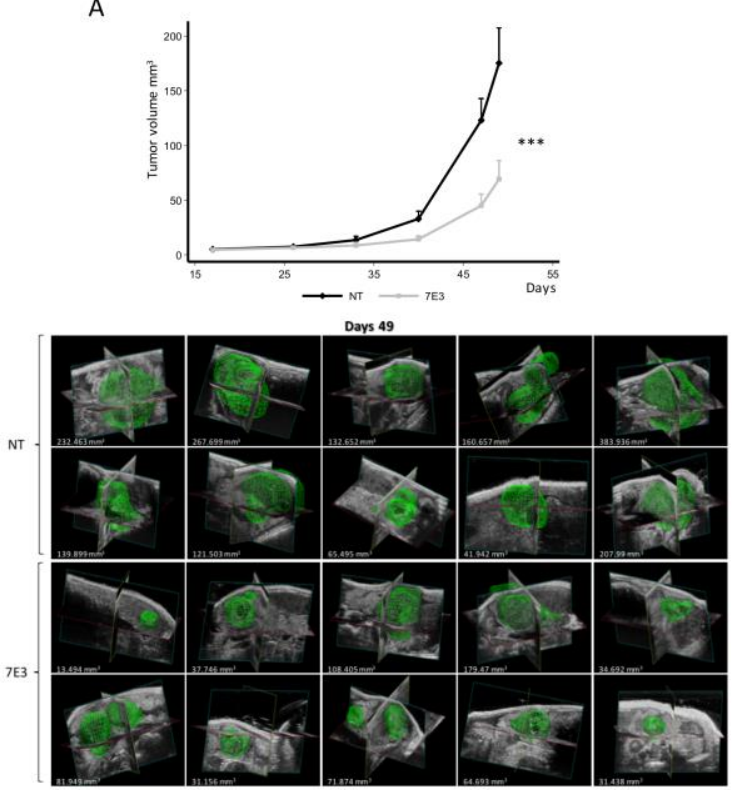
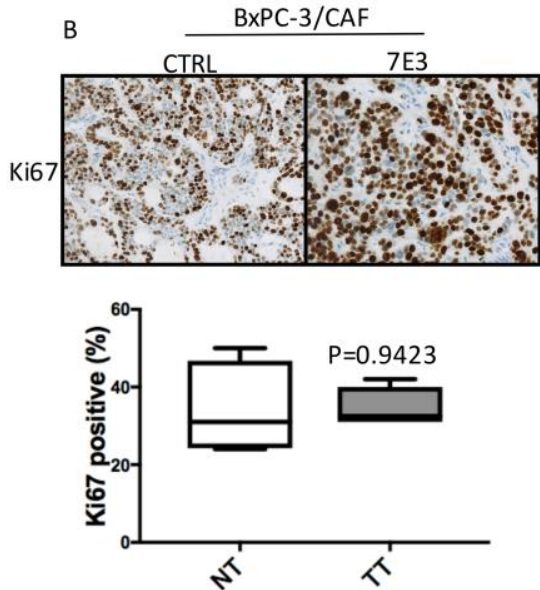

(A) BXPC-3 cells and CAFs were injected at a 1:2 ratio in the pancreas of athymic mice ( $n=10$ per group). After 7 days, mice were treated or not (NT) with $10 \mathrm{mg} / \mathrm{kg}$ of $7 E 3$ twice per week for 6 weeks. Tumor volume was measured by ultrasonography. The data of tumor volume measured by of of Ki67 in 7E3 treated tumors and saline treated controls.

Supplemental Figure S4 